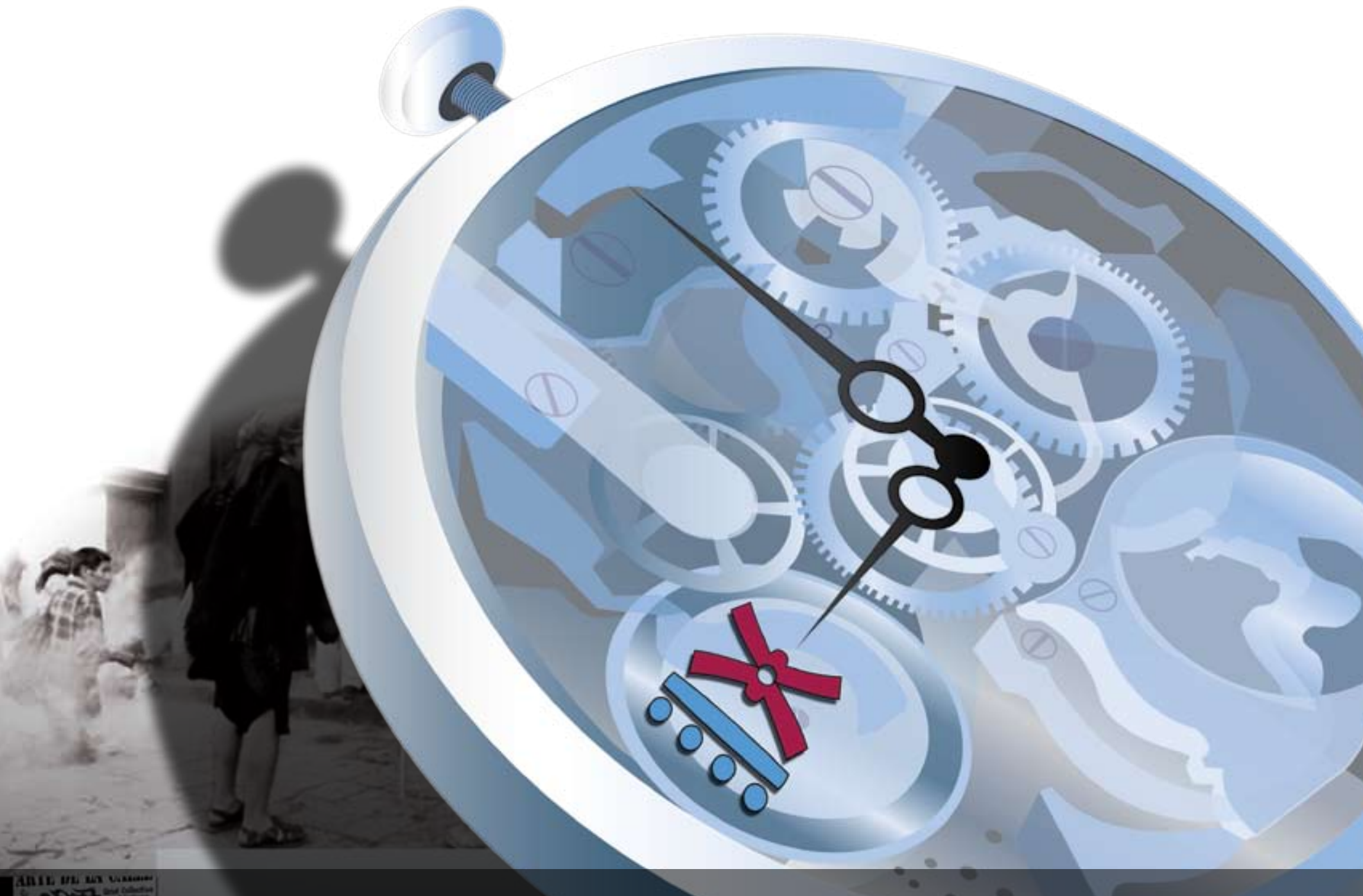

O $99^{\circ}$ C O N G R S O 2. CENTROAMERICANO DE HISTOR I A

Universidad de Costa Rica

ISSN 1409-469X

Fecha de recepción: 15 de mayo 2008 Fecha de aceptación: 30 de mayo 2008

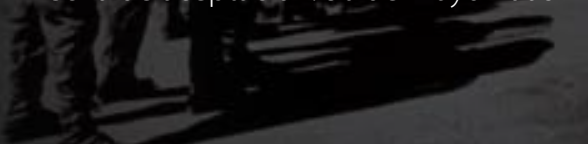

\section{Las escrituras testimoniales:} ¿aparatos de la Memoria?

Miembros del Consejo Editorial:

Dr. Ronny Viales, Dr. Juan José Marín

Editores Técnicos:

Allan Fonseca, Andrés Cruz, Gabriela Soto
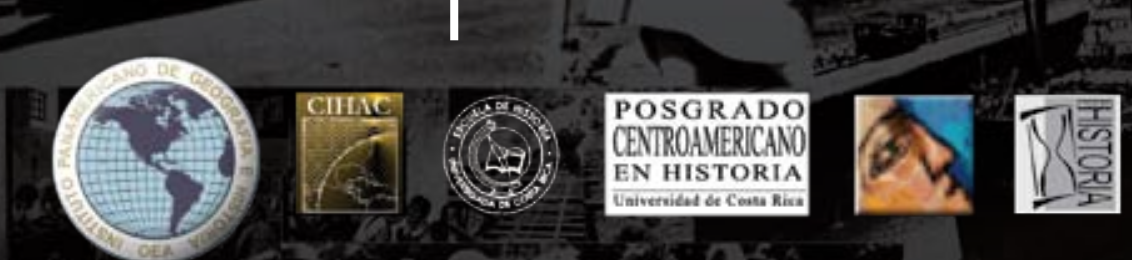


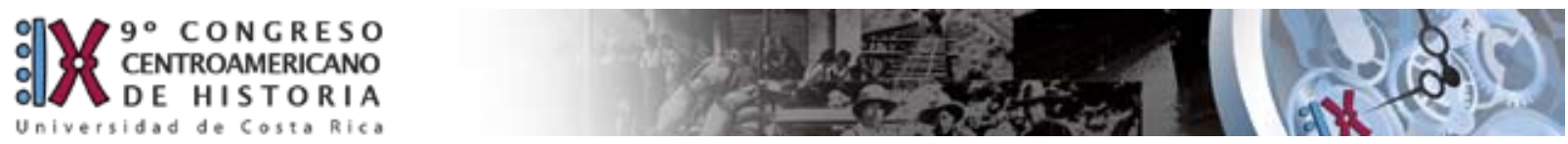

Indexaciones: Repositorio de Revistas UCR, DIALNET, Latindex, REDALYC Directorio y recolector de recursos digitales del Ministerio de Cultura de España, Directory of Open Access Journals. Diálogos Revista Electrónica de Historia ISSN 1409-469X. Número especial 2008. Dirección web: http://historia.fcs.ucr.ac.cr/dialogos.htm

\title{
Las escrituras testimoniales: ¿aparatos de la Memoria?
}

\author{
José Miguel Vargas Ramírez
}

Dirección: San Miguel de Santo Domingo de Heredia

Teléfono: 22-40-69-27 o 88-33-61-55

Correo electrónico: jmvarraz@gmail.com

Afiliación Institucional: Bachiller en Filología Española, estudiante de la Licenciatura en Filología Española con énfasis en Literatura por la Universidad de Costa Rica, 


\section{La anécdota de Cardenal}

Quiero iniciar esta ponencia con un fragmento tomado del tomo tercero de las memorias de Ernesto Cardenal, titulado La Revolución Perdida. Este fragmento del que les hablo constituye la parte final del capítulo trece, titulado a su vez "Viviendo en la casa de Somoza".

Antes de citar textualmente deseo parafrasear la anécdota narrada por Cardenal. Cuenta que el día en que llegó a Nicaragua la noticia del ajusticiamiento de Somoza la gente se lanzó a las calles y fue una verdadera fiesta nacional. En esa misma fecha sucedió un acontecimiento extraño: el chilamate (árbol inmenso que puede vivir y crecer indefinidamente) plantado en el patio de la casa de Somoza cayó estrepitosamente mostrando sus raíces podridas.

Cuenta que al día siguiente un periodista francés le preguntó si encontraba una relación entre la caída del árbol y la muerte de Somoza, y que él respondió que era posible, pues es bien sabido que las plantas agradecen a quienes las cuidan. En esta misma jornada, Ernesto Cardenal refiere el hallazgo de Enrique descalabrado en medio de la copa del árbol caído; Enrique es un papagayo cuyo nombre se debe a que esta palabra es la única que repite. Un detalle importante es que Enrique pudo haber pertenecido a un miembro de la guardia nacional (es decir, una lapa somocista) o a un guerrillero muerto (a sea, una lapa sandinista).

Por último, narra la tristeza sentida por los miembros del Ministerio de Cultura a causa de la caída del bello árbol, y cuanta cómo después de podar ramas y raíces el árbol fue re-sembrado y, con ello, re-vivido. Es en este punto en el que termina el capítulo, cuyo final deseo citar textualmente: "Volvió a vivir una nueva vida, sin la pudrición que había tenido, y para mí fue un símbolo de la nueva Nicaragua sin el somocismo. Bajo sus ramas volvió a estar otra vez alegre Enrique, repitiendo un nombre que pudo haber sido de guardia o tal vez de guerrillero." 1

1 Cardenal, E. La Revolución Perdida. (Managua, Anama Ediciones Centroamericanas, 
He querido introducir el tema con este fragmento por considerarlo un ejemplo del modo en que Textualidad y Memoria se manifiestan. En primer lugar se hace patente en este trozo de escritura la particular elección y disposición del material lingüístico, gracias a lo cual "ÁRBOL CON RAÍCES PODRIDAS" equivale a "SOMOZA", mientras que "ÁRBOL REVIVIDO" equivaldría a "NUEVA NICARAGUA", es decir, "SANDINISMO". También es importante el elemento "ENRIQUE", cuya significancia se desplaza de "LAPA SOMOCISTA" a "LAPA SANDINISTA" añadiendo al "ÁRBOL REVIVIDO" el adjetivo de "PLURALISTA". En segundo lugar, es evidente que la narración posee un factor subordinante, del cual dependen los elementos ya señalados. Tal factor se expone en el "Y PARA MÍ" que asigna el sentido a los elementos del discurso; es decir, este discurso es dependiente de la instancia Yo. En tercer lugar es clara la correlación entre eventos de la esfera social con el aspecto lingüístico, por la cual podemos prever una orientación del texto en función de la esfera extra-literaria.

En un intento por sintetizar lo anterior puedo establecer la siguiente afirmación: la Textualidad y la Memoria se manifiestan por su construcción, su artificialidad y su función. Para entender a cabalidad este postulado es preciso cerrar esta introducción y proceder a aclarar los problemas con él relacionados.

\section{La perspectiva de la poética: Textualidad y Memoria}

Estamos acostumbrados a tratar la literatura como se trata un espejo, es decir, a considerar su reflexividad. Las consecuencias de este saber común hacen que la lectura equivoque el material de trabajo: se quiere trabajar sobre el acontecimiento histórico que tal o cual libro refleja, o sobre la práctica social a la cual se anexa cual o tal libro.

2004), 444 
Y si bien es cierto existe una articulación entre lo literario y las demás esferas de la vida, ella no es objeto sencillo de analizar, y mucho me temo que esas lecturas especulares poca luz arrojan tanto sobre lo literario como sobre lo histórico-político-social que el texto supuestamente alberga.

A diferencia de lo anterior, lo que la poética, según los formalistas, plantea es "la literatura considerada como una serie específica de hechos." En su artículo "La teoría del método formal", Eichenbaum nos invita a pensar al menos dos modos de análisis literario: el genético, que se enfoca en la pesquisa de los orígenes del texto, y el de la poética, que se enfoca en el estudio de la artificialidad, la construcción y la función del texto literario.

Yo he querido en esta ponencia trasladar a la Memoria estos tres elementos que los formalistas otorgan al texto, con el interés de formular una plataforma de lectura que permita analizar la escritura testimonial como aparato de la Memoria.

Pero ¿qué se entiende por artificio, construcción y función? Por artificio debemos entender el desplazamiento de lo literario desde la inventio hacia la dispositio. Para Shklovsky: "Todo el trabajo de las escuelas poéticas no es otra cosa que la acumulación y revelación de nuevos procedimientos para disponer y elaborar el material verbal, y consiste más en la disposición de las imágenes que en su creación.”’3 Es decir, la artificialidad del texto es su disposición particular del material lingüístico.

En cuanto a la construcción, hablamos de la integración del material lingüístico en un orden dinámico dentro del cual habrá siempre un factor subordinante y constructivo. Para Tinianov: "El factor promovido deforma a los que se le subordinan. Se puede decir entonces que

2 Eichenbaum, B.M. "La teoría del 'método formal", en Teoría de la literatura de los formalistas rusos. (Argentina, Siglo XXI Editores, 2004), 22

3 Shlovsky, V. "El arte como artificio", en Teoría de la literatura de los formalistas rusos. (Argentina, Siglo XXI Editores, 2004), 56. 
siempre se percibe la forma en el curso de la evolución de la relación entre el factor subordinante y constructivo y los factores subordinados." 4

Por lo que atañe a la función, nos referiremos a la relación entre la serie literaria y la serie vecina, sea esta histórica-sociológica-política. La función es, pues, la articulación entre la serie literaria y lo exterior a ella, lo que llaman los formalistas la vida social. Según el mismo Tinianov “La vida social entra en correlación con la literatura ante todo por su aspecto verbal (...) Esta correlación entre la serie literaria y la serie social se establece a través de la actividad lingüistica; la literatura tiene una función verbal en relación con la vida social.” 5

La terna conceptual apuntada permite desarrollar una lectura de los textos literarios a través del análisis de sus componentes lingüísticos. La pregunta que nace en este punto es ¿cómo tratar la Memoria desde esta perspectiva?

Para responder esta pregunta debo aclarar primero a cuál memoria me refiero, porque puedo apostar que existen muchos modos de la Memoria. Me refiero a la memoria que producen los textos, la que se pone en marcha por la articulación de los textos en la serie literaria y por la articulación de esta serie con las series de lo social.

No me refiero a la memoria de Ernesto Cardenal, nostálgico de la Revolución y apartado en Solentiname; no me refiero a la memoria colectiva del pueblo revolucionario. No me refiero, en consecuencia, a la Memoria Histórica, aunque mucho de histórico tenga esta producción textual de la Memoria por cuanto pueda instalarse en un eje diacrónico.

Hablo entonces de una memoria textual, o mejor del texto como aparato de la Memoria. Pensar al texto desde esta posición tiene consecuencias que es necesario analizar; por ello,

4 Tinianov, I. "La noción de construcción", en Teoría de la literatura de los formalistas rusos. (Argentina, Siglo XXI Editores, 2004), 88

$5 \quad$ "Sobre la evolución literaria", en Teoría de la literatura de los formalistas rusos. (Argentina, Siglo XXI Editores, 2004), 97-98 
en el siguiente apartado abordo esta dinámica mediante un comentario en torno al testimonio centroamericano.

\section{Las escrituras testimoniales como aparatos de la Memoria}

El testimonio como práctica de escritura ha generado una extensa discusión por parte de la crítica. Si bien abundan los estudios el concepto sigue siendo problemático, sobre todo en lo tocante a su género. Para Elzbieta Sklodowska: "Despite all the critical attention it has received, testimonio remains undefined. In this case, the notion of genre is clearly 'historically derived' rather than 'logically prescribed' (Lohafer 1983, II), and testimonio serves as shorthand for a hall spectrum of narrative conventions." ${ }^{\circ}$

El problema de los límites del género testimonio ha provocado la creación de diferentes categorías mediante las cuales se busca clasificar la diferencia de los textos. Así, podemos tener testimonios, novelas testimoniales, novela-testimonio o testi-novela según la categorización del crítico. Esta diferenciación queda mejor explicada con las siguientes palabras tomadas de la misma Sklodowska:

La denominación «novela testimonial» constituye un intento por diferenciar esta modalidad de otras formas posibles del testimonio (memoria, diario, crónica) y de la novela. La palabra «testimonio» refleja una intención de dar prioridad a los elementos no ficticios. Esta pretensión de una autenticidad histórica emparienta a la novela testimonial con una variedad de obras

6 Sklodowska, E. "Spanish american testimonial novel: some aftertoughts", en The real thing. (Estados Unidos, Duke University Press, 1996), 84. 
(«las verdaderas historias», biografías, reportajes), pero la resolución estético ideológica de este común propósito de testimoniar varía mucho según la época y la posición ideológica del autor.?

En efecto, si observáramos las escrituras testimoniales podríamos dar fe de las palabras de Sklodowska: las diferencias entre los testimonios centroamericanos y otras producciones escritas, como la crónica, la verdadera historia, o incluso las novelas contemporáneas que utilizan una "apariencia de testimonio", colocan al lector frente al problema de situar el manejo que el texto da a la realidad y a la ficción.

La mayoría estará de acuerdo en diferenciar el testimonio dado por un indígena acerca de los asesinatos y desapariciones sucedidas durante los conflictos bélicos, del testimonio que un personaje novelesco haga sobre el mismo tema, a pesar de que ambos productos lingüísticos posean la misma carga de verdad.

La crítica ha querido resolver esta diferencia a través de un acercamiento genético: ha intentado establecer el origen del testimonio, quién lo dice, quién lo escribe, etc. Esta pesquisa del origen, como ya he dicho en otra parte, ha permitido aislar algunos elementos característicos del testimonio en general. Sklodowska explica, por ejemplo, el procedimiento de Miguel Barnet: "Barnet ofrece su fórmula testimonial: registrar imparcialmente las memorias de un sujeto representativo de un grupo y participante de un acontecer colectivo, transcribir fielmente la oralidad del discurso, recalcar el polo «realista» o «empírico» dentro del molde novelesco." ${ }^{\text {" No }}$ obstante, esta misma crítica, por su interés genético, pierde de vista un análisis apegado al texto

$7 \quad$ Sklodowska, E. "Miguel Barnet y la gente sin historia", en Acerca de Miguel Barnet. (La Habana, Editorial Letras Cubanas, 2000), 31-32.

8 Sklodowska, E. "Miguel Barnet y la gente sin historia", en Acerca de Miguel Barnet. (La Habana, Editorial Letras Cubanas, 2000), 33. 
para divertirse en conjeturar cuánto ha desvirtuado o no el autor el testimonio dado.

Para mí ese divertimento no basta. Al considerar al testimonio he preferido ahondar la lectura desde otra perspectiva; la perspectiva que he venido dando desde el inicio: la poética. Creo que para una lectura desde la poética lo primero que debemos hacer es reconsiderar la finalidad crítica del análisis sobre el testimonio: No debemos enfocarnos más en la diferencia de las producciones escritas, sino en aquellos elementos que posean en común.

Con esto quiero proponer la eliminación de las categorías testimonio, novela testimonial, crónica, memoria, testi-novela, etc. para promover una sola categoría que abarque el conjunto de estas producciones y, quizás, de otras por venir: esta categoría será la escritura testimonial.

Para la escritura testimonial importa el producto lingüístico como tal, y no el anclaje de la producción. La escritura testimonial borra así los límites entre la realidad y la ficción, por ello reconoce la carga de verdad de los enunciados independientemente del hablante.

Quiero hacer patente que esto no es un acto de lesa humanidad: no se trata de disminuir al ser humano que da cuenta de los hechos, sino de atacar esos mismos hechos desde diversos campos de la producción sígnica.

Las palabras anteriores van de la mano con la propuesta de Abdeslam Azougarh: "Para la novela-testimonio, conviene mejor no enfocar la realidad y la ficción de manera antagónica y abandonar el argumento ontológico a favor del funcionalista. De suerte que, en lugar de ser simplemente lo contrario de la realidad, la ficción nos comunica algo acerca de la realidad.” ${ }^{9}$

Ahora bien, en adelante no detallaré el concepto de escritura testimonial, sino que indagaré cómo esas producciones escritas constituyen un aparato de la Memoria. Ya he dicho que busco la memoria producida por la articulación de los textos, por ello debo enfrentar una preguntas:

9 Azougarh, A. "La recepción de la novela testimonio de Miguel Barnet", en Acerca de Miguel Barnet. (La Habana. Editorial Letras Cubanas, 2000), 74. 
¿Cómo se articula la escritura testimonial en la serie literaria?

En la serie literaria, las escrituras testimoniales se articulan por su construcción: el factor subordinante es siempre la primera persona singular. Este Yo de las escrituras testimoniales es una marca de diferencia frente a otras producciones textuales, porque él es ante todo la máscara de una pluralidad, es un Yo que diluye su individualidad para ser representación del colectivo; recordemos el modo en que Sklodowska hablaba de la fórmula de Barnet: "Barnet ofrece su fórmula testimonial: registrar imparcialmente las memorias de un sujeto representativo de un grupo y participante de un acontecer colectivo...”"10

En esta misma dirección apunta John Beverly: "The "I" that speaks to us in de picaresque or first-person novel is in general precisely the mark of a difference or antagonism with the community (...) The narrator in testimonio, on the other hand, speaks for, or in the name of, a community or group, aproximating on this way the simbolic function of the epic hero, without in the same time assuming his hierarchical and patriarchal status." ${ }^{11}$

Tal articulación es lo que observamos concretarse en el "y para mí" de Ernesto Cardenal, comentado en la introducción. Este "y para mí” subordina el conjunto de elementos lingüísticos del texto, los distribuye y, con ello, les otorga un significado particular.

Sin embargo, no debemos perder de vista que tal subordinación de los elementos por un Yo sólo es posible por el valor comunal de ese Yo: es en la medida en que Yo representa a la comunidad revolucionaria -y por ende a la comunidad que cambia el sentido- que puede erigirse como factor constructivo del texto.

La consecuencia directa de una articulación de los textos en la serie literaria por su factor

10 Sklodowska, E. (2000) "Miguel Barnet y la gente sin historia”, en Acerca de Miguel Barnet. Editorial Letras Cubanas: La Habana.

11 Beverly, J. “The margin at de center: On testimonio", en The real thing. (Estados Unidos, Duke University Press, 1996),27. 
constructivo es el fortalecimiento de esta articulación por su artificialidad. Recordemos que el "y para mí" dispone los elementos de la siguiente manera: "árbol con raíces podridas" = "Somoza", "árbol revivido" = "nueva Nicaragua" = "sandinismo" = "pluralismo", otorgando así una significación determinada a los elementos.

La anterior es la manifestación más básica de la artificialidad de los textos que conforman la serie literaria. Puedo decir de ella que es particular de las escrituras testimoniales por cuanto esta 'dispositio' de los elementos lingüísticos se propone re-ordenar los valores sígnicos con miras a un nuevo marco de sentido; lo cual se comprende mejor al ligar artificialidad con función de las escrituras testimoniales.

De la mano con lo referido, existe otra manifestación de la artificialidad en las escrituras testimoniales, de mayor peso a mi parecer cuando se trata de vincular los textos de la serie. Esta es el modo particular en que las escrituras testimoniales re-ordenan los valores que la institucionalidad ha fijado sobre lo literario, lo cual es explicado por Azougarh de la siguiente manera:

El uso discreto de los modos canónicos de narrar trata de «automatizar» la narración en la mente del lector para desembocar en la «desautomatización» del concepto mismo de literatura. La presencia del autor, de su trabajo literario, reside en su aparente ausencia. (...) De modo que la ficción no es, forzosamente, lo contrario de la realidad, sino una manera determinada de su mediación. En la novela-testimonio, la realidad gana gracias a la ficción, a que esta organiza aquella para hacerla más comunicable y más real. Gracias a la ficción, paradójicamente, 
el relato gana verosimilitud. ${ }^{12}$

Este es el modo en que pienso la articulación de los textos en la serie literaria. La pregunta que se destaca es ¿qué hace de las escrituras testimoniales aparataos de la Memoria?, ¿cómo produce memoria la articulación de los textos?

Se hacen aparatos de la Memoria en la medida en que son una re-disposición de los valores sígnicos; en la medida en que los elementos lingüísticos se ordenan para manifestarse como un cambio de sentido. Esto implica que no podamos clasificar la Memoria como algo concreto y estático, sino como una aparición producida por el modo en que se construye y distribuye la vida sígnica de las sociedades y los sujetos: la Memoria aparece en los modelos de significación, pero aparece más cuando esos modelos son conflictuados a través de un re-ordenamiento de sus elementos constitutivos.

De esta forma podemos entender el modo en que la escritura testimonial, a través de su articulación en la serie literaria, produce una memoria. No obstante, como aparato de la Memoria estas producciones escritas se expresan también mediante su articulación con la vida social. En la medida en que comprendamos cómo se articula la serie literaria con la serie de lo social justificaremos mejor loas afirmaciones anteriores

A mi parecer, lo más particular de la escritura testimonial es que consolida su articulación en la serie literaria a través de su articulación con la serie de lo social, o bien, mediante su función. Observé que la función de un texto radica en su aspecto verbal, en el nexo de la actividad lingüística con la vida social. La actividad lingüística de estas producciones textuales es, precisamente, la testimonial, el acto de dar testimonio mediante el re-ordenamiento de los

12 Azougarh, A. "La recepción de la novela testimonio de Miguel Barnet", en Acerca de Miguel Barnet. La Habana, Editorial Letras Cubanas, 2000), 66-74. 
valores sígnicos puesto en conflicto.

En este sentido, puedo afirmar que la función testimonial de estas escrituras se encuentra estrechamente ligada con la Memoria por cuanto el testimonio introduce en el modelo discursivo el conflicto necesario para la aparición de la Memoria. Para concretar el postulado anterior, volvamos a la anécdota de Ernesto Cardenal, en esta oportunidad vinculemos el aspecto testimonial de esa anécdota con la vida social, es decir, con el proceso revolucionario sucedido en Nicaragua.

Entiendo por revolución una acción sostenida en contra de lo hegemónico. La hegemonía es, en principio, un ordenamiento de los valores sígnicos al servicio de un modelo de dominación. Swingewood, partiendo del concepto gramsciano de hegemonía, expone:

Así, una clase dominante se define como aquella que ha impregnado a la sociedad con su moralidad, sus costumbres, sus prácticas religiosas y políticas (...) Por lo tanto en las sociedades capitalistas y socialistas los valores hegemónicos se difunden por medio de aquellas instituciones que se han incluido comúnmente bajo el rubro de "superestructura" (religiosas, educativas, etc.) y es por medio de ellas que los individuos se socializan para aceptar la legitimidad de la ideología dominante. Otras instituciones "superestructurales" (la literaria, por ejemplo) refractan y transmutan estos valores en forma más general a las obras

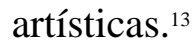

De esta manera entre la vida social y la serie literaria existe un ligamen merced al quiebre del orden hegemónico. De la mano con el proceso revolucionario, que buscaba re-construir o 13 Swingewood, A. Novela y Revolución. (México, Fondo de Cultura Económica, 1988), 71-72 
re-distribuir la estructura política, social e histórica de Nicaragua, se produce un conjunto de productos textuales que, mediante un re-ordenamiento de los valores sígnicos, re-construye y re-distribuye la hegemonía del sentido en función de una nuevo marco de significación.

A causa de lo anterior la articulación de la serie literaria con la serie de lo social consolida el funcionamiento de la escritura testimonial como aparato de la Memoria, por cuanto es gracias al carácter anti-hegemónico de la escritura testimonial que la Memoria puede aparecer en la práctica lingüística. En nuestro caso de estudio, la Memoria aparece al poner en contradicción dos momentos históricos: "vieja Nicaragua/nueva Nicaragua, y dos momentos políticos: monolitismo político/pluralismo político.

\section{Apuntes finales sobre la Memoria}

Este conjunto de ideas es, por ahora, todo lo que puedo ahondar sobre la escritura testimonial y su relación con la Memoria; no obstante, me resulta pertinente intentar una especie de síntesis en torno a la percepción que he dado.

En principio, lo que es más interesante destacar en torno a la Memoria producida por la escritura testimonial es que ella es una manifestación de la contradicción introducida en los marcos de significación, ya sean estos propios de la serie literaria como propios de la vida social. Por lo que tiene de re-distribución y re-construcción esta Memoria resulta ilocalizable, por ello la he caracterizado como una aparición: la re-distribución no es necesariamente un hecho histórico, la reconstrucción no es obligatoriamente un acontecimiento socio-político, ambos procesos pueden acaecer en la más radical cotidianidad y, por ello, la Memoria es un suceso vinculable con la Cultura, la Ideología y la Textualidad, entre muchos otros objetos aún difíciles de definir. 
En un segundo momento, me resulta importante destacar que, por las características destacadas, es posible transferir a la Memoria un modelo de análisis utilizado para la Textualidad. Es decir, podemos abordar la Memoria como abordamos las diversas manifestaciones del lenguaje, no para reducirla a la lengua o al discurso, sino para desnudar lo que haya de sígnico en ella, para señalar que algo de su materialidad radica en la significación.

Por último, deseo culminar esta ponencia afirmando algo que, estoy seguro, todos aquí sabemos y, por esta misma razón , no podemos dejar de repetir: la Memoria y la Textualidad son fenómenos que desbordan por mucho los modelos que la institucionalidad - expresión concreta del poder- impone sobre los sujetos; este es el motivo por el cual ambas pueden aparecer como manifestaciones anti-hegemónicas. En este sentido, no parece vano un acontecimiento como el presente, que busca unir en un diálogo la Historia y la Literatura, sabiendo que ambos espacios se movilizan tarde o temprano hacia los límites de la dominación. 